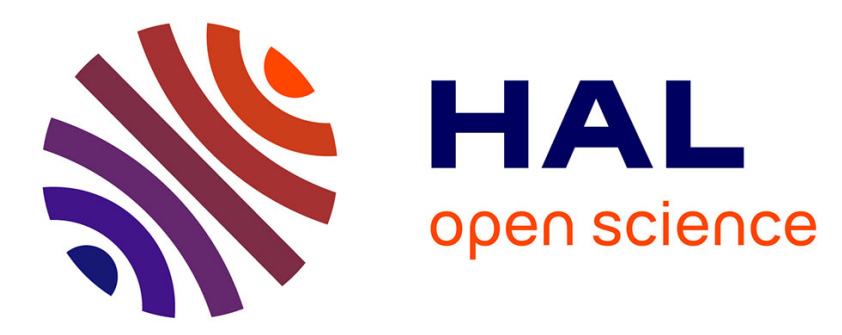

\title{
Global disturbance of the transient magnetic field associated to thermospheric storm winds on March 23, 1979
}

\author{
O. Fambitakoye, M. Menvielle, C. Mazaudier
}

\section{- To cite this version:}

O. Fambitakoye, M. Menvielle, C. Mazaudier. Global disturbance of the transient magnetic field associated to thermospheric storm winds on March 23, 1979. Journal of Geophysical Research, 1990, pp.209-218. hal-00976076

\section{HAL Id: hal-00976076 https: / hal.sorbonne-universite.fr/hal-00976076}

Submitted on 9 Apr 2014

HAL is a multi-disciplinary open access archive for the deposit and dissemination of scientific research documents, whether they are published or not. The documents may come from teaching and research institutions in France or abroad, or from public or private research centers.
L'archive ouverte pluridisciplinaire HAL, est destinée au dépôt et à la diffusion de documents scientifiques de niveau recherche, publiés ou non, émanant des établissements d'enseignement et de recherche français ou étrangers, des laboratoires publics ou privés. 


\title{
Global Disturbance of the Transient Magnetic Field Associated With Thermospheric Storm Winds on March 23, 1979
}

\author{
O. Fambitakoye \\ Laboratoire de Géophysique, Institut Français de Recherche Scientifique pour le Développement en Coopération \\ Bondy, France
}

M. Menvielle

Laboratoire de Géomagnétisme, Institut de Physique du Globe, Paris

\section{MAzaudier}

Centre National d'Etudes des Télécommunications/Centre de Recherche sur la Physique de l'Environnement Saint Maur des Fossés, France

\begin{abstract}
During large magnetic storms, wind disturbances produced by auroral phenomena can affect the whole thermospheric circulation and associated ionospheric dynamo currents for many hours after the end of the storm. This paper presents a morphological analysis of the ground magnetic field disturbance related to the storm winds observed on March 23, 1979, the day after the Coordinated Data Analysis Workshop (CDAW) 6 events. The disturbance in the magnetic field variations is observed on a planetary scale, and its pattern does not correspond to that of the regular field variations related to the undisturbed atmospheric dynamo.
\end{abstract}

\section{INTRODUCTION}

Up to the end of the 1950 s the only data available to investigate the ionized environment of the Earth were recordings of the transient variations of the Earth's magnetic field made at ground stations. The extensive study of these variations led many observers to postulate the existence of external current systems in the Earth environment $\left(S_{R}\right.$ and $S q$ currents, ring currents, tail currents, magnetopause currents, $D P 2$ currents, substorm currents, field-aligned currents, and auroral electrojets, etc.).

However, knowledge of the variations of the geomagnetic field at ground stations alone does not enable one to determine the three-dimensional distribution of these currents. Nevertheless, by assuming a perfectly resistive atmosphere between the conductive solid Earth and ionosphere, it is possible to account for the observations in terms of the gradient of a scalar harmonic function. The upward continuation of this function up to the ionospheric conductive shell provides the geometry of the ionospheric equivalent currents. These currents are the only information which can be derived from ground-based stations alone, without further hypothesis.

During the last two decades, in situ measurements made by spacecraft (satellites, rockets, balloons) or radar provided direct information about the physics of the Earth's environment. Large advances in Earth electrodynamic studies became possible with these new in situ data sets (see Kamide [1988] for a review of these results), and we now have a more detailed and complete picture of the geometry of the electric fields and currents in the Earth's ionosphere and magnetosphere. In particular, it is now well established that the

Copyright 1990 by the American Geophysical Union.

Paper number 90JA00033.

0148-0227/90/90JA-00033\$05.00 day-to-day variability of the magnetic daily variation is due mainly to the ionospheric currents induced by thermal convection in the upper atmosphere [e.g., Mayaud, 1982; Mazaudier, 1989].

The goal of this paper is to analyze the magnetic field variations caused by the storm atmospheric wind dynamo. This dynamo process has been studied theoretically by Richmond and Matsushita [1975] and Blanc and Richmond [1980]. Mayaud [1982] was the first to interpret magnetic variations (the attenuation of the magnetic effects of the equatorial electrojet observed during quiet days after a magnetic storm) as a result of this dynamo action. Such magnetic perturbations can easily be seen only during selected days after storms when (1) the auroral activity is weak and (2) large storm winds are observed blowing in the low thermosphere [Mazaudier, 1985; Mazaudier et al., 1985]. These conditions have been verified for March 23, 1979, our selected case.

The chosen period, March 21-23, 1979, includes the sixth Coordinated Data Analysis Workshop (CDAW 6) event (March 22, 1979). This event was extensively studied by CDAW 6, the primary goal of which "was to trace the flow of energy from the solar wind through the magnetosphere to its ultimate dissipation in the ionosphere" [McPherron and Manka, 1985, p. 1175]. A part of the February 1985 issue of the Journal of Geophysical Research is devoted to the results of CDAW 6.

The major part of the experimenters' data analysis concerned the solar wind/magnetosphere interaction, or magnetosphere/auroral zone coupling. Mazaudier [1985] studied the auroral/mid-latitude electrodynamic coupling by using the Saint-Santin (France) incoherent scatter sounder. She showed that on March 22, mid-latitude thermospheric winds were weakly affected by the storm. The disturbed electric field observations can therefore be interpreted as mainly due 

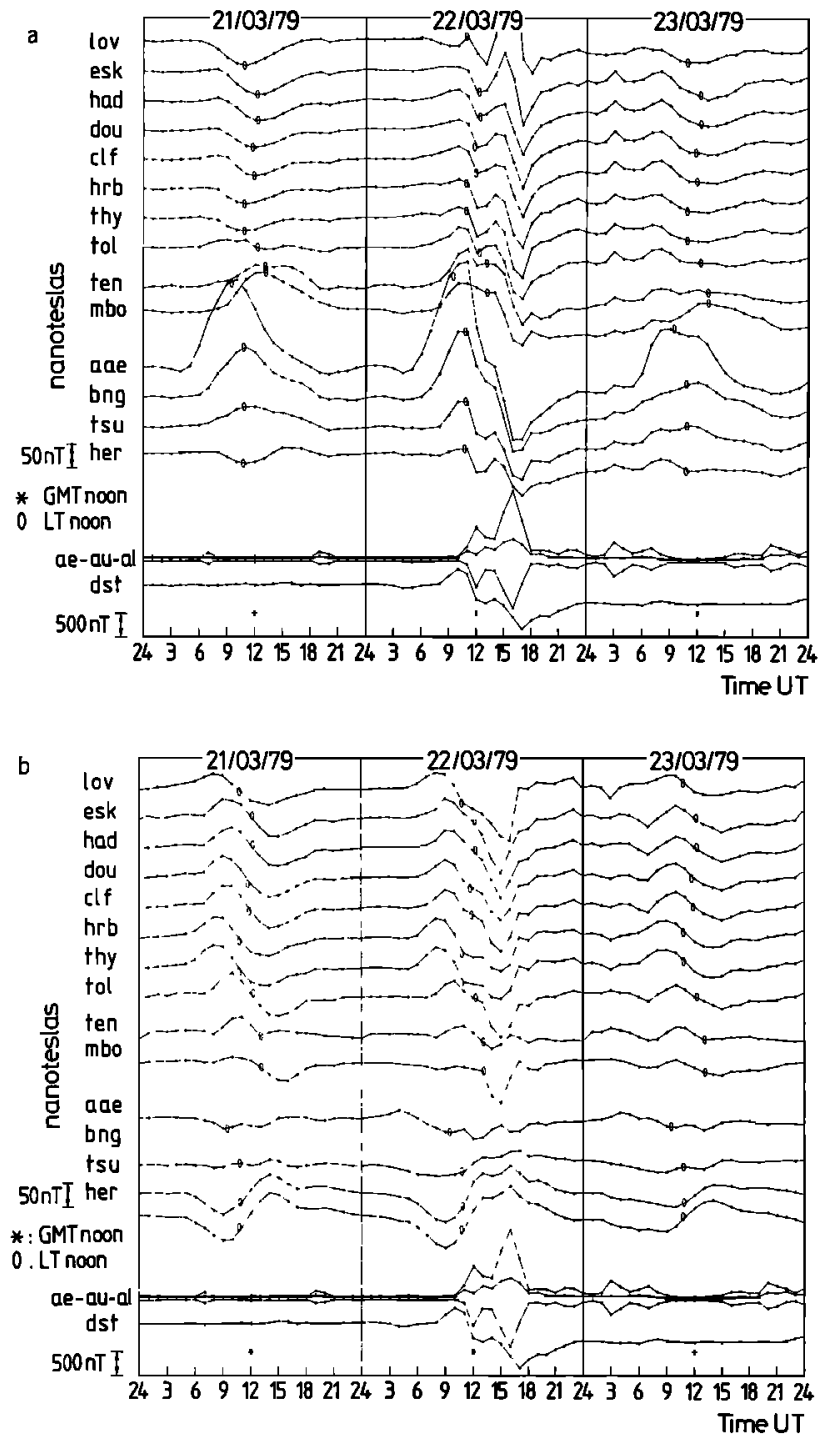

Fig. 1. Observed transient variations in geographic $(a)$ north $(X)$ and $(b)$ east $(Y)$ components of the Earth's magnetic field at a meridian chain of European/African longitudes, on March 21-23, 1979 (see Table 1 and Figures 6-8 for the location of the observatories). The magnetic storm related to the CDAW 6 events started on March 22, at 0826 UT. $A U, A L, A E$, and $D s t$ variations are plotted at the bottom of the figure ( 0 for local noon).

to direct penetration of magnetospheric convection electric field [Vasyliunas, 1970, 1973]. This interpretation was confirmed by Senior and Blanc [1987] using a semiempirical model.

In contrast, on March 23, although the auroral activity was weak (see Figure 1), large southward winds were observed above Saint-Santin [see Mazaudier, 1985, Figure 8]. Such wind observations are interpreted as the signature of Hadley cell(s) between the pole and the equator, built up by the storm Joule dissipation at auroral zones [Reddy, 1974; Mazaudier et al., 1985]. Mazaudier et al. suggested that the electric field and current disturbances observed on March 23, 1979, were mainly due to the storm wind dynamo action.

Besides, Taïeb and Poinsard [1984] analyzed the variation of electron density in the $E$ and $F$ layers during the period March 20-25. They found a decrease in electron density on March 23 only at altitudes above $250 \mathrm{~km}$ during the daytime.
The decrease is related to storm winds and electric disturbance.

In section 2 we recall some definitions concerning our study and the relation between ionospheric currents and the magnetic field. We describe and analyze the magnetic data set in section 3. We then derive from our observations some features of the disturbed ionospheric dynamo (section 4) and discuss them (section 5).

\section{IONOSPHERIC CURRENTS AND GRoUND MAGNETIC VARIATIONS}

Ionospheric currents circulating in the $E$ region account for most of the variations in the Earth's magnetic field. The relationship between these variables can be derived from Ampere's law. It was put forward by Chapman and Bartels [1940]:

$$
|\Delta B|=(2 \pi / 10 f)|J|
$$

where $B$ is expressed in nanoteslas (nT) and $J$ in amperes per kilometer. A corrective factor $f$ takes ground current effects into account; it is usually taken equal to 0.6 [e.g., Kamide and Brekke, 1975].

The ionospheric current density $\mathbf{J}$ is related to ionospheric electric current and neutral winds through the ionospheric Ohm's law:

$$
\mathbf{J}=\sigma\left(\mathbf{E}+\mathbf{V}_{n} \times \mathbf{B}\right)
$$

where $\sigma$ is the conductivity tensor, $\mathbf{E}$ the electric field, $\mathbf{V}_{n}$ the neutral winds, and $B$ the magnetic field.

During magnetic quiet periods the regular variations of ionospheric electrodynamic parameters $\left(\sigma_{r}, \mathbf{E}_{r}, \mathbf{V}_{n r}, \mathbf{J}_{r}\right)$ are mainly due to the regular ionospheric dynamo. This dynamo arises from the coupling between several physical processes: absorption of the solar UV radiation, motion in the atmosphere, and collision processes between neutral atmosphere and ionized particles. At middle and low latitudes the ionospheric currents in the $E$ region are mainly generated by the regular ionospheric dynamo. The corresponding variation in the magnetic field is the daily variation. It presents a significant day-to-day variability, which has been extensively described by Mayaud [1967]. The variation observed at a given station on a given day is called the $S_{R}$, following Mayaud [1965a, b, 1982]; the average of the $S_{R}$ over a month, a season, or a year is the well-known $S q$.

Mid-latitude electric fields, neutral winds, electron density, and therefore electric currents can be changed during and after active magnetic periods. These disturbances result from the direct coupling with the magnetospheric electric field in auroral zones. They extend on a planetary scale through two processes: the penetration of the convection electric field on the one hand and the ionospheric disturbance dynamo on the other.

During magnetic quiet periods following a storm the only disturbance effects remaining are those associated with the ionospheric dynamo. The disturbance primarily affects neutral winds and electrical fields, which in turn act on the ionization. The total ionospheric electric current, $\mathbf{J}_{t}$, can be expressed as

$\mathbf{J}_{l}=\mathbf{J}_{r}+\Delta \mathbf{J}=\left(\sigma_{r}+\Delta \sigma\right)\left[E_{r}+\Delta \mathbf{E}+\left(\mathbf{V}_{n r}+\Delta \mathbf{V}_{n}\right)+\mathbf{B}\right]$

where $\Delta \sigma, \Delta \mathbf{E}$, and $\Delta \mathbf{V}_{n}$ are disturbances of the electrodynamic parameters due to storm effects. 
TABLE 1. List of the Observatories Used in This Study

\begin{tabular}{|c|c|c|c|c|c|}
\hline \multirow[b]{2}{*}{ Code } & \multirow[b]{2}{*}{ Name } & \multicolumn{2}{|c|}{$\begin{array}{l}\text { Geographic } \\
\text { Coordinates }\end{array}$} & \multicolumn{2}{|c|}{$\begin{array}{l}\text { Geomagnetic } \\
\text { Coordinates }\end{array}$} \\
\hline & & Latitude & Longitude & Latitude & Longitude \\
\hline AAE & Addis Ababa & 9.03 & 38.77 & 5.19 & 110.97 \\
\hline ASH & Ashkhabad & 37.95 & 58.10 & 30.58 & 134.62 \\
\hline BNG & Bangui & 4.43 & 18.57 & 4.45 & 90.33 \\
\hline CLF & $\begin{array}{c}\text { Chambon la } \\
\text { Forêt }\end{array}$ & 48.02 & 2.27 & 50.06 & 85.71 \\
\hline CZT & Crozet & -46.43 & 51.87 & -51.49 & 111.46 \\
\hline DOU & Dourbes & 50.10 & 4.60 & 51.60 & 88.99 \\
\hline ESK & Eskdalemuir & 55.32 & 356.80 & 58.04 & 84.07 \\
\hline FRD & Fredericksburg & 38.20 & 282.63 & 49.13 & 352.23 \\
\hline GUA & Guam & 13.58 & 144.87 & 4.57 & 214.76 \\
\hline HAD & Hartland & 50.98 & 355.52 & 54.17 & 80.29 \\
\hline HER & Hermanus & -34.42 & 19.23 & -33.73 & 82.67 \\
\hline HON & Honolulu & 21.32 & 202.00 & 21.46 & 268.57 \\
\hline HRB & Hurbanovo & 47.87 & 18.18 & 46.89 & 101.07 \\
\hline HYB & Hyderabad & 17.42 & 78.55 & 7.86 & 150.69 \\
\hline KNY & Kanoya & 31.42 & 130.88 & 21.12 & 199.85 \\
\hline KGD & Karaganda & 49.82 & 73.08 & 40.56 & 150.04 \\
\hline KOD & Kodaikanal & 10.23 & 77.47 & 0.81 & 148.93 \\
\hline LNN & Leningrad & 59.95 & 30.70 & 56.14 & 118.32 \\
\hline LOV & Lovo & 59.35 & 17.83 & 57.84 & 106.75 \\
\hline LNP & Lunping & 25.00 & 121.17 & 14.21 & 191.28 \\
\hline MBO & Mbour & 14.40 & 343.02 & 20.68 & 56.80 \\
\hline OTT & Ottawa & 45.40 & 284.45 & 56.37 & 354.11 \\
\hline PPT & Papeete & -17.55 & 210.38 & -15.09 & 284.44 \\
\hline PAF & Port aux Français & -49.35 & 70.22 & -57.31 & 130.79 \\
\hline SJG & San Juan & 18.38 & 293.88 & 29.36 & 5.21 \\
\hline SGE & South Georgia & -54.28 & 323.52 & -44.82 & 27.73 \\
\hline TKT & Tashkent & 41.33 & 69.62 & 32.51 & 145.52 \\
\hline THY & Tihany & 46.90 & 17.90 & 46.01 & 100.41 \\
\hline TEN & Tenerife & 28.48 & 343.72 & 34.60 & 60.30 \\
\hline TOL & Toledo & 39.88 & 355.95 & 43.39 & 76.18 \\
\hline TRD & Trivandrum & 8.48 & 76.95 & -0.88 & 148.24 \\
\hline TSU & Tsumeb & -19.22 & 17.70 & -19.59 & 94.83 \\
\hline
\end{tabular}

The codes are those of the International Association of Geomagnetism and Aeronomy.

On March 23, 1979, the auroral activity was weak. One can then neglect the penetration of magnetospheric electric field. Besides, the large southward disturbed winds observed at Saint-Santin [Mazaudier, 1985] may indicate the presence of an ionospheric disturbance dynamo process. However, Taïeb and Poinsard [1984] showed that the electron density changes only above $250 \mathrm{~km}$. The electric currents are mainly below $200 \mathrm{~km}$. We can therefore neglect $\Delta \sigma$ in equation (1).

\section{The Magnetic Data}

It has been shown that at subauroral latitudes the solar regular variation $\left(S_{R}\right)$ can be described to within an accuracy better than $1 \mathrm{nT}$ using the fundamental 24-hour mode and its first four harmonics [e.g., Menvielle et al., 1987]. The same result clearly holds at all latitudes, and the $S_{R}$ day-to-day variability can therefore be investigated on a planetary scale using hourly mean values published in the yearbooks of magnetic observatories.

The data used in this study are the hourly mean values of the horizontal components of the geomagnetic field observed at a network of observatories given in Table 1. At almost all stations the published values correspond to the magnetic north and east horizontal components of the magnetic field. In order to avoid the bias related to the variation of the magnetic declination from one station to the other, we
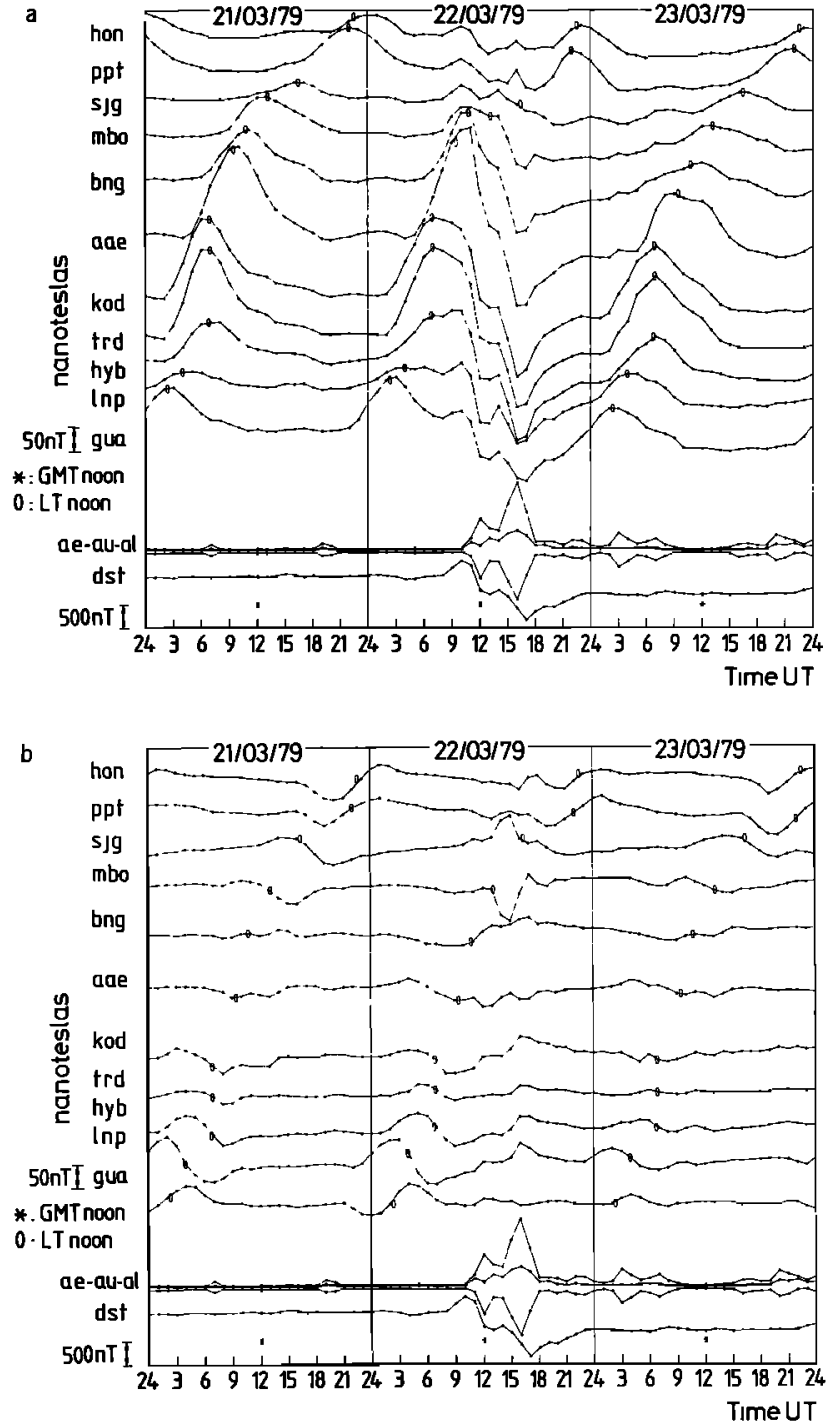

Fig. 2. Observed transient variations in geographic $(a)$ north $(X)$ and $(b)$ east $(Y)$ components of the Earth's magnetic field at a tropical chain of low-latitude observatories, on March 21-23, 1979 (see Table 1 and Figures $6-8$ for location of the observatories). The magnetic storm related to the CDAW 6 events started on March 22, at 0826 UT. $A U, A L, A E$, and $D s t$ variations are plotted at the bottom of the figure.

computed at these stations the variations of the geographic north $(X)$ and east $(Y)$ horizontal components of the geomagnetic field.

\subsection{Elimination of the Irregular Variations}

Figures 1 and 2 show the observed $X$ and $Y$ variations at a north-south chain of European/African longitude observatories (hereinafter called the meridian chain) and an east-west chain of low-latitude observatories (hereinafter called the tropical chain), on March 21-23, 1979. These figures also present the variations of the $D s t$ and $A E$ indices. Table 2 gives also the values of hourly Dst, $A E$, and 3-hourly am indices during these three days (see Mayaud [1980] for a description of these indices).

There is almost no magnetospheric activity during the UT March 21 day: the daily index $A m$ value is $9 \mathrm{nT}$ (Table 2), 
TABLE $2 a$. Hourly $D s t$ and $A E$ Geomagnetic Activity Indices for March 20-24, 1979

\begin{tabular}{|c|c|c|c|c|c|c|c|c|c|c|c|c|c|c|c|c|c|c|c|c|c|c|c|c|}
\hline \multirow[b]{2}{*}{ Day } & \multicolumn{24}{|c|}{ Universal Time } \\
\hline & 1 & 2 & 3 & 4 & 5 & 6 & 7 & 8 & 9 & 10 & 11 & 12 & 13 & 14 & 15 & 16 & 17 & 18 & 19 & 20 & 21 & 22 & 23 & 24 \\
\hline \multicolumn{25}{|l|}{20} \\
\hline Dst & 7 & 3 & 0 & -2 & 0 & 3 & 5 & 5 & 8 & 10 & 11 & 9 & 7 & 5 & 7 & 7 & -1 & 1 & 2 & 4 & 3 & 12 & 16 & 14 \\
\hline$A E$ & 63 & 62 & 66 & 86 & 64 & 139 & 225 & 170 & 218 & 203 & 85 & 59 & 76 & 70 & 66 & 69 & 129 & 108 & 110 & 62 & 48 & 100 & 67 & 67 \\
\hline \multicolumn{25}{|l|}{21} \\
\hline Dst & 14 & 14 & 12 & 14 & 15 & 15 & 13 & 14 & 15 & 16 & 17 & 15 & 15 & 17 & 20 & 19 & 14 & 17 & 14 & 14 & 15 & 16 & 16 & 18 \\
\hline$A E$ & 65 & 62 & 52 & 53 & 49 & 49 & 146 & 59 & 54 & 47 & 50 & 65 & 58 & 56 & 71 & 57 & 61 & 60 & 166 & 119 & 44 & 43 & 58 & 60 \\
\hline \multicolumn{25}{|l|}{22} \\
\hline Dst & 18 & 16 & 14 & 9 & 10 & 14 & 15 & 17 & 33 & 47 & 37 & -14 & -22 & -13 & -26 & -50 & -74 & -57 & -47 & -48 & -37 & -30 & -22 & -20 \\
\hline$A E$ & 55 & 57 & 51 & 62 & 73 & 59 & 53 & 45 & 71 & 74 & 273 & 656 & 463 & 425 & 970 & 1390 & 800 & 198 & 202 & 191 & 129 & 216 & 211 & 118 \\
\hline \multicolumn{25}{|c|}{ 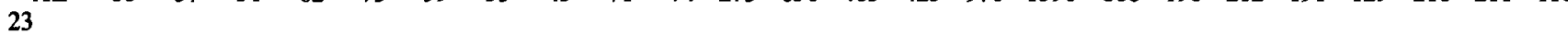 } \\
\hline Dst & -20 & -21 & -23 & -24 & -23 & -25 & -19 & -16 & -19 & -21 & -23 & -23 & -20 & -21 & -24 & -23 & -21 & -23 & -21 & -21 & -22 & -20 & -14 & -10 \\
\hline$A E$ & 86 & 125 & 372 & 244 & 150 & 192 & 258 & 134 & 78 & 42 & 34 & 45 & 45 & 61 & 84 & 146 & 152 & 120 & 120 & 328 & 259 & 206 & 125 & 220 \\
\hline \multicolumn{25}{|c|}{ 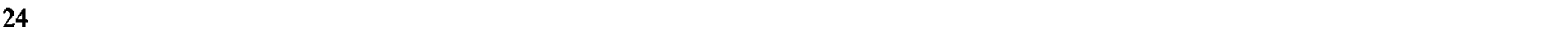 } \\
\hline Dst & -9 & -14 & -16 & -13 & -11 & -13 & -18 & -18 & -28 & -38 & -30 & -29 & -31 & -32 & -31 & -24 & -19 & -21 & -20 & -16 & -16 & -14 & -9 & -12 \\
\hline$A E$ & 273 & 191 & 145 & 149 & 174 & 126 & 214 & 437 & 571 & 326 & 63 & 57 & 65 & 120 & 169 & 131 & 119 & 231 & 245 & 187 & 340 & 340 & 308 & 430 \\
\hline
\end{tabular}

and variations of hourly $D s t$ and $A E$ indices remain smaller than 20 and $166 \mathrm{nT}$, respectively (Figures 1 and 2). This UT day is therefore a very quiet day, and the observed transient variations are those of the $S_{R}$ variation generated by atmospheric tidal motions.

On March 22, at 0826 UT, a magnetic storm started which lasted about 10 hours. Its onset corresponds to a positive variation in Dst, followed some hours later by a sharp increase in $A U$ and $A L$ intensity. The morphology of the associated irregular activity depends on universal time whereas that of the $S_{R}$ depends on local time [Mayaud, 1967] (Figure 2). The intense auroral activity stops at about $18 \mathrm{UT}$. The 3-hour am indices are of the order of 100-120 nT during the storm and then decrease to 20-40 nT on March 22 (evening) and March 23; Dst recovers a constant level at the beginning of the UT March 23 day, but this level is $35 \mathrm{nT}$ lower than that observed on March 21.

This magnetic storm is followed by a fairly quiet magnetic situation, with weak auroral activity. On March 23, variations in Dst remain smaller than $25 \mathrm{nT}$ (Figures 1 and 2), and the daily $A m$ index is $19 \mathrm{nT}$ (Table $2 a$ ).

As expected, Dst variations are present in the variations of the $X$ component but not in those of the $Y$ component (Figures 1 and 2). In order to cancel out these ring current origin variations, we computed at each observatory the differences $X-D s t \cos L$, where $L$ is the geomagnetic dipole latitude of the station (Figure 3 ). The variations of these differences result from both $S_{R}$ and auroral origin activity, as do those of the $Y$ component. Since the auroral activity is weak on March 21 and 23, $X-D$ st $\cos L$ and $Y$ variations can be used to study the $S_{R}$ variability between these two days.

TABLE $2 b$. Three-Hourly am Geomagnetic Activity Indices for March 20-24, 1979

\begin{tabular}{rrrrrrrrrrr}
\hline & \multicolumn{8}{c}{$a m$} & \\
\cline { 2 - 7 } Day & $1-3$ & $4-6$ & $7-9$ & $10-12$ & $13-15$ & $16-18$ & $19-21$ & $22-24$ & Am \\
\hline 20 & 10 & 14 & 12 & 7 & 8 & 9 & 9 & 13 & 10 \\
21 & 4 & 5 & 10 & 5 & 10 & 7 & 17 & 13 & 9 \\
22 & 5 & 8 & 46 & 95 & 118 & 123 & 38 & 30 & 58 \\
23 & 29 & 23 & 22 & 13 & 14 & 16 & 19 & 19 & 19 \\
24 & 17 & 18 & 35 & 28 & 15 & 16 & 22 & 34 & 23 \\
\hline
\end{tabular}

\subsection{The Magnetic Effect of the Ionospheric Irregular Dynamo}

The $S_{R}$ day-to-day variability is related to both the dayto-day variability of the regular ionospheric dynamo and the thermospheric winds resulting from Joule heating at auroral latitudes during magnetospheric storms (the irregular dynamo [e.g., Blanc and Richmond, 1980; Mazaudier, 1989]). It is related to the day-to-day variability of winds, electric fields, and conductivity (see equation (1)). Averaging the $S_{R}$ variations observed during the quiet magnetic days in a given time interval leads to the $S q$ variation, which corresponds to the mean regular dynamo. The difference $S_{R}-S q$ is then related to both regular and irregular dynamo, and it cannot be used to characterize the magnetic effects of the ionospheric irregular dynamo.

Besides, the day before and the day after the March 22 magnetospheric storm are quiet magnetic days, for which the $S_{R}$ variation is well defined (see section 3.1 and Figure 1). The difference $\Delta S_{R}$ between the $S_{R}$ variations observed before and after the storm would characterize the irregular dynamo provided the contribution of the regular dynamo in the day-to-day variability of the $S_{R}$ remains negligible in comparison with that of the irregular dynamo during these three days.

The day-to-day variability in the neutral winds associated with the regular dynamo has been extensively studied by Bernard [1978], who showed that it may be as large as their seasonal variability. Very few quantitative results are available about the related magnetic effects. However, morphological considerations clearly show that (1) they do not significantly affect the geometrical pattern of the $S_{R}$ variation and (2) they remain in general significantly smaller than the effects of the seasonal variability. In contrast, the magnetic variations related to the irregular dynamo may be as large as the seasonal variability in the $S_{R}$ and significantly modify its geometrical pattern [Mayaud, 1965a, $b, 1982$ ].

The difference $\Delta S_{R}$ therefore enables one to characterize the magnetic effects of the irregular dynamo; such a morphological analysis would help us to discuss its origin. Figures 4 and 5 show the variations of these differences computed for the observatories of the meridian and tropical chains, respectively. 

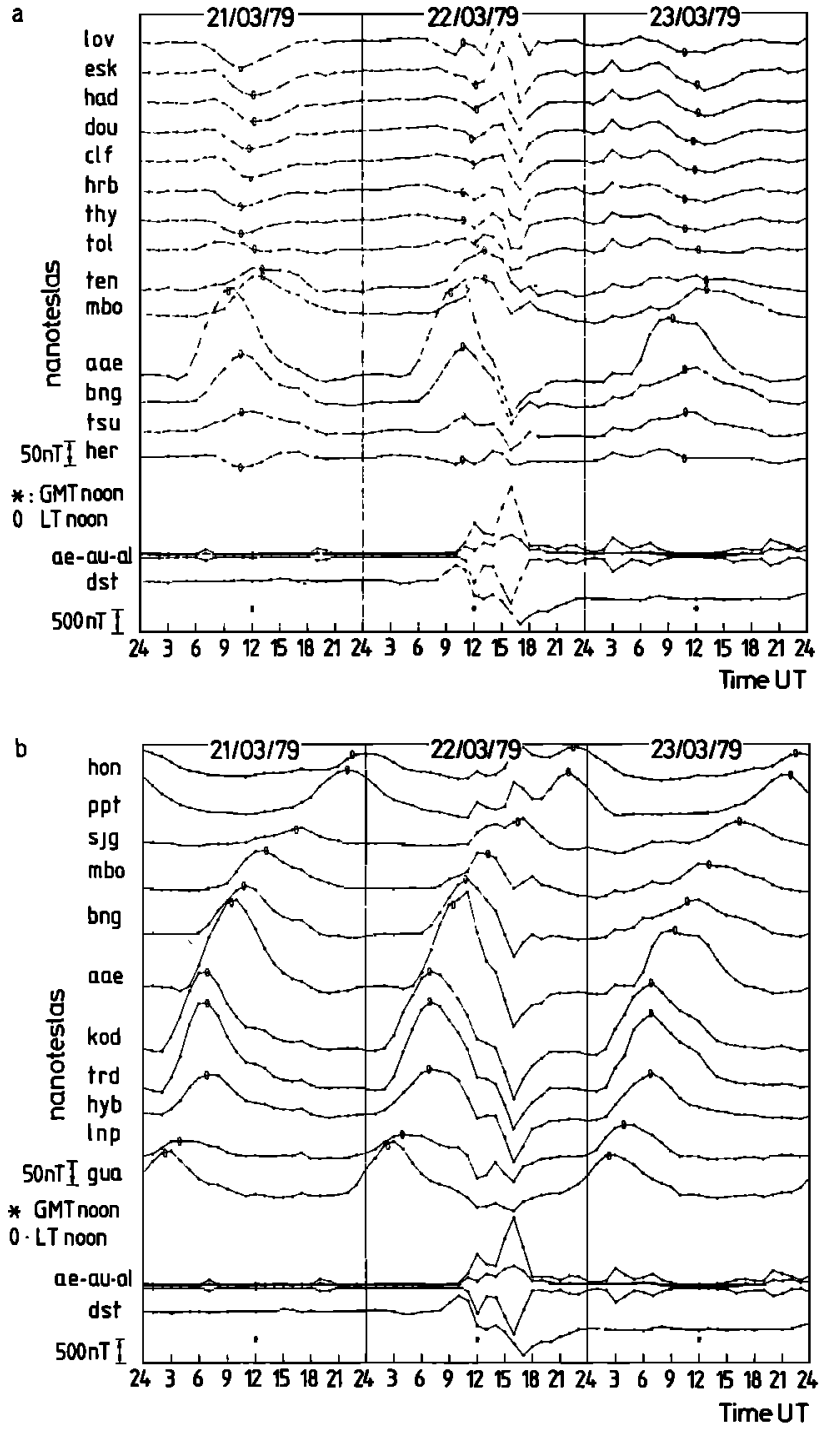

Fig. 3. Variations in the geographic north component corrected for ring current effects using the $D s t$ index at the stations of the meridian and the tropical chain (see text and Figures 1 and 2 for further explanations).

The ionospheric conductivity vanishes during the night, as does the transient magnetic field associated with the neutral winds. Therefore the study of these differences does not enable us to characterize the neutral winds which may exist during the night, and the night level corresponds to the zero level for the $\Delta S_{R}$ differences. In practice, we define at each station the zero level as the average of the $\Delta S_{R}$ hourly mean values corresponding to the hours between 22 and 02 LT during the nights before and after the day under study, for which the hourly $A E$ index remains smaller than $150 \mathrm{nT}$.

Figures 4 and 5 show significant variations in $\Delta S_{R}$ for both $X$ and $Y$ components. The morphology of these variations is different from that of the $S_{R}$ on March 21 and 23 (see Figures 1-3), thus indicating the presence on March 23 of magnetic effects related to the disturbed ionospheric dynamo, on a planetary scale. These effects are dependent on both LT and UT, as expected for effects resulting from a perturbation in the thermal wind circulation resulting from heating in the auroral zone during the storm. They are particularly intense at equatorial stations (e.g., BNG, AAE, KOD, and TRD; see
Figure 5), where they were first pointed out by Mazaudier and Venkateswaran [1990].

\section{The Disturbed Ionospheric Dynamo}

With the assumption of currents flowing in a spherical conductive ionospheric shell, the horizontal magnetic perturbation vectors are perpendicular to the current lines and linearly related to the integrated intensity $J$ [e.g., Chapman and Bartels, 1940; Kamide, 1988]. We have thus established

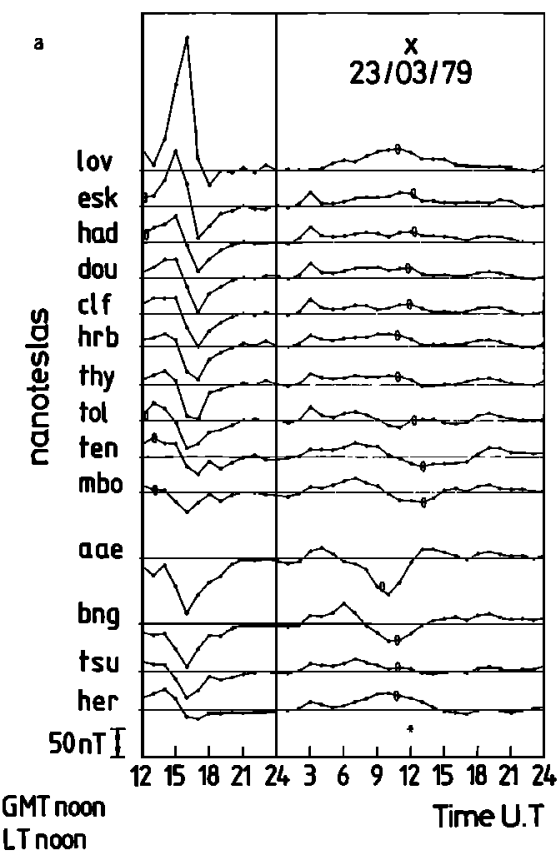

b

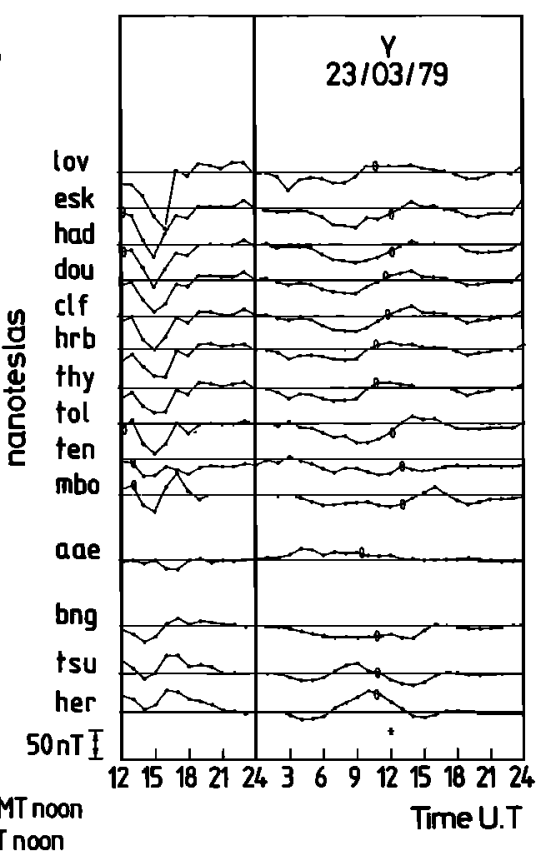

Fig. 4. Difference between the variations observed on the day before and the day after the CDAW 6 events at the stations of the meridian chain: (a) geographic north component corrected for ring current effects, (b) geographic east component. For each curve the straight line corresponds to the zero level as estimated using $A E$ indices (see text for further explanations). 

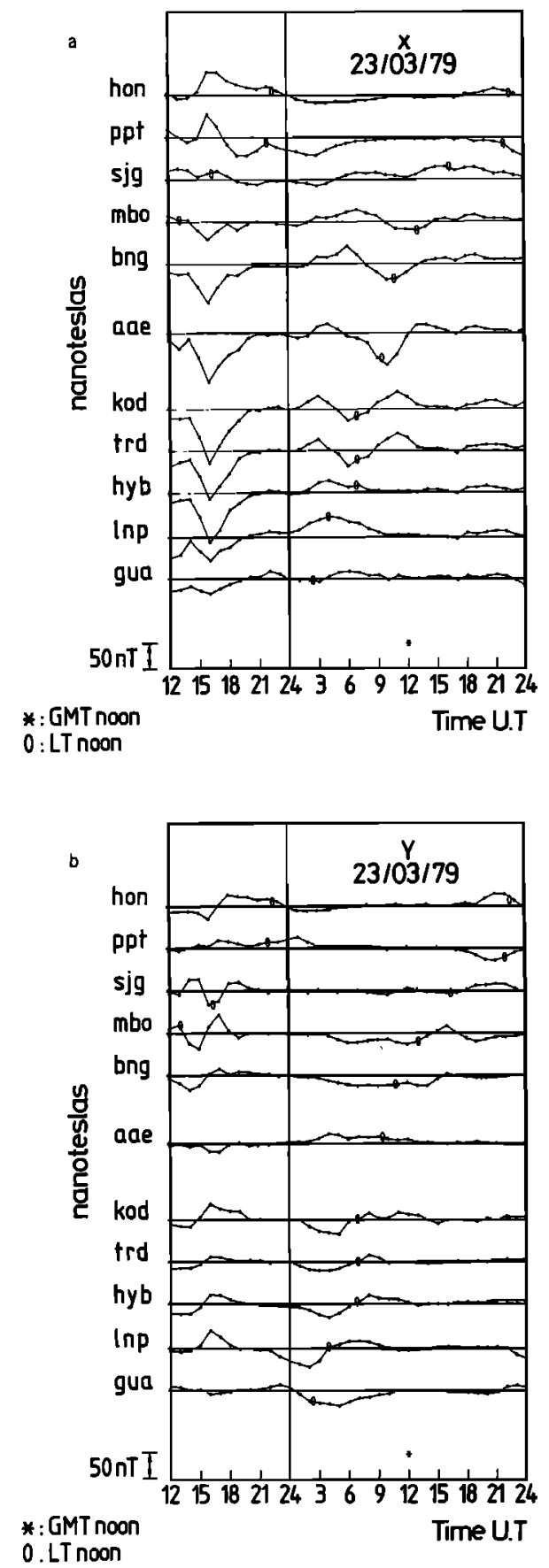

Fig. 5. Difference between the variations observed on the day before and the day after the CDAW 6 events at the stations of the tropical chain: (a) geographic north component corrected for ring current effects; (b) geographic east component.

maps of the perturbation $\Delta J$ in the equivalent ionospheric currents, corresponding to the observed perturbation $\Delta S_{R}$ in the solar regular variation. These $\Delta J$ currents correspond to the ionospheric current disturbances due to the storm wind dynamo action.

In order to describe the disturbed ionospheric dynamo on a planetary scale, we have produced maps of the $\Delta J$ perturbation observed during a given UT interval at all the observatories of the network described in Table 1 . These maps show that the $\Delta J$ currents are organized on a planetary scale, but with a geometry which evolves with time.

Significant $\Delta J$ currents may have existed over the Pacific Ocean just after the storm, late in the March 22 UT evening and early in the March 23 UT morning (e.g., PPT and HON; see Figure 5). However, since most of the stations were on the nightside at that time, we have no information about the geometry of these currents.

Figure 6 shows the $\Delta J$ currents at 06 and 07 UT in the morning on March 23. During this period the $\Delta J$ currents are mainly zonal, positive eastward. In the southern hemisphere there is some evidence for the existence of a counterclockwise vortex of currents centered around local noon. This vortex, which extends far to the north of the dip equator, seems to deflect the main zonal flow of currents. The main features of the $\Delta J$ geometry remain the same during 2-3 hours, but the focus of the vortex drifts toward the afternoon in local time.

Figure 7 shows the $\Delta J$ currents at 11 and 12 UT on March 23. There is no longer evidence for a zonal current flow. Instead, a clockwise vortex of currents is centered on local noon in the northern hemisphere, and it appears that a counterclockwise one is centered on the afternoon sector in the southern hemisphere. The northern vortex extends far to the south of the dip equator. Furthermore, there seems to be some connection between the two vortices.

In the UT afternoon, at 15 and 16 UT (Figure 8), the currents are less intense, and their pattern suggests the existence of structures of smaller scale than before, without clear organization.

Thus perturbations related to the irregular dynamo remain significant during at least 15 hours. During about 10 hours after the storm the current flow remains organized on a planetary scale, with a predominant zonal component. Then the scale of the current structures decreases, and vortices of smaller and smaller size appear. Finally, it is worth noticing that at any time, $\Delta J$ currents flow across the dip equator and that in some cases, north-south $\Delta J$ currents, corresponding to east-west $\Delta S_{R}$ field, are observed at equatorial stations (e.g., BNG at 08 and 13 UT; see Figure 5).

\section{Discussion}

We have considered in this paper the case of a storm occurring between two days of magnetic quiet. Eliminating the Dst variations and computing the difference between the $S_{R}$ of the day after and that of the day before the storm enables us to depict the global pattern of the magnetic effects of the disturbed ionospheric dynamo resulting from that storm. Our analysis shows that they correspond, at mid latitudes, to electric current flows reversed from those responsible for the solar regular variation ("anti- $S_{R}$ " current cells) and, at equatorial latitudes, to westward current flows inducing "counterelectrojet" effects [Gouin and Mayaud, 1967; Fambitakoye and Mayaud, 1976] at ground stations. Furthermore, invasions of one hemisphere by the opposite hemisphere current system are observed, with related strong meridian flow across the equator.

All these features can be interpreted together, as recently shown by Stening [1989], who pointed out similar features on particular quiet days and interpreted them in terms of $S(2$, 3) atmospheric tide effects. On the other hand, one numerical simulation provided evidence that "anti- $S_{R}$ " cells may 


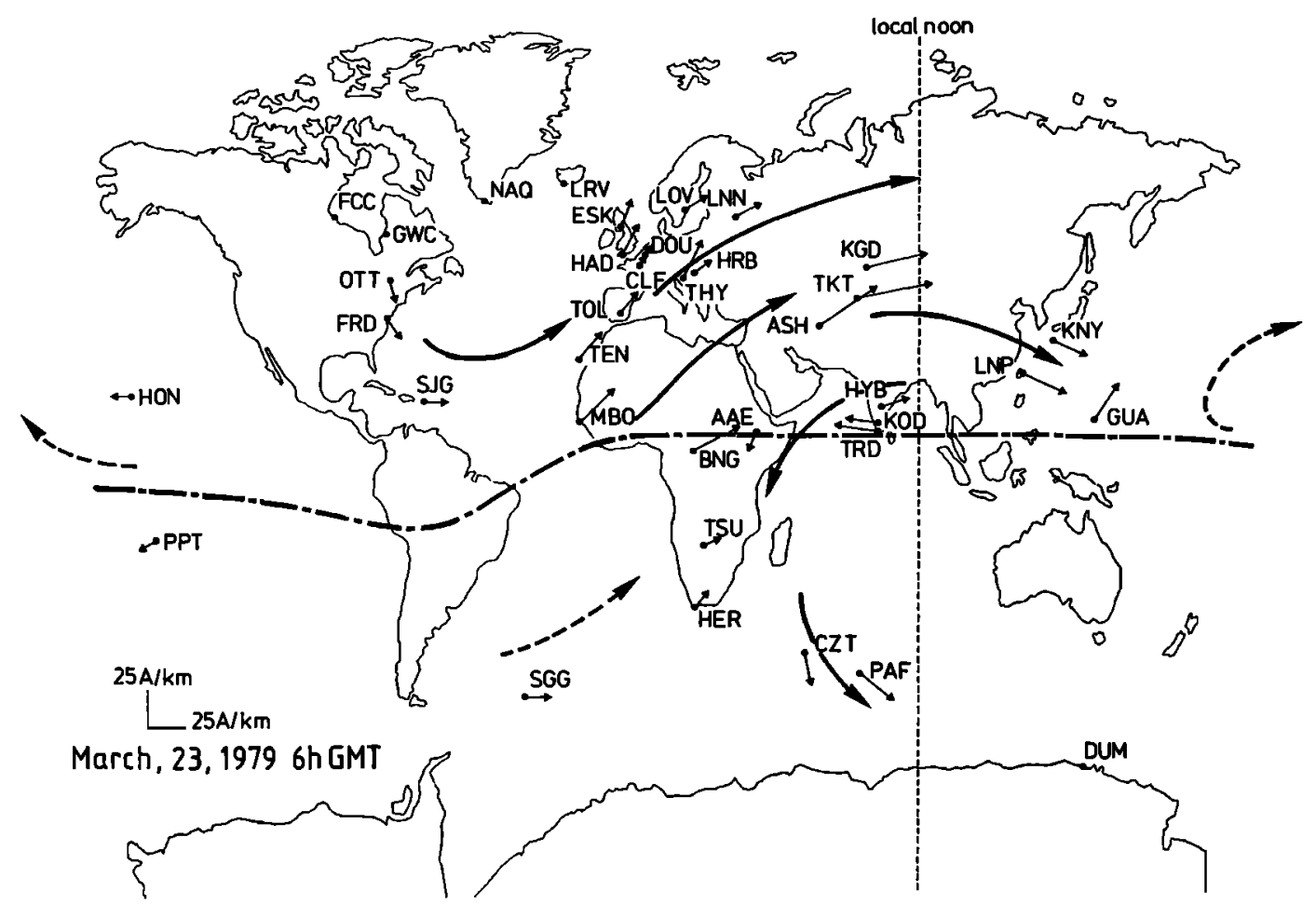

Fig. $6 a$

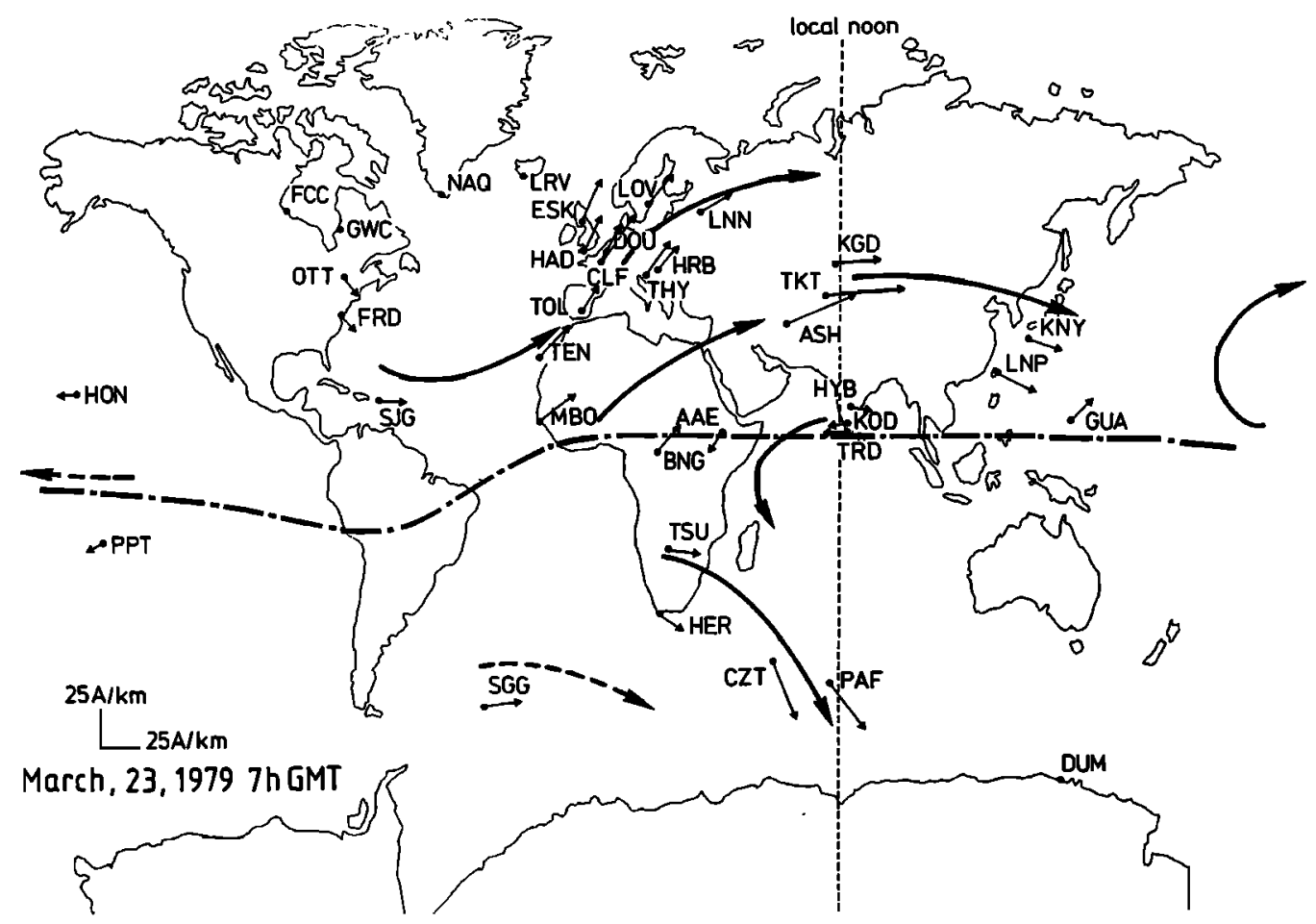

Fig. $6 b$

Fig. 6. Ionospheric equivalent currents related to the disturbed dynamo during the March 23, 1979, UT morning. The thin arrows correspond to the integrated density of currents deduced from the observed magnetic field variations. The trends of the current flow on a planetary scale are indicated by the thick arrows (solid, fairly well defined; dashed, doubtful). The dash-dot line indicates the dip equator, and the thin vertical line indicates local noon.

result at mid latitudes from disturbed ionospheric dynamo process [Blanc and Richmond, 1980]. However, this numerical simulation assumed the complete closing of the currents through an equatorial electrojet a priori located between $10^{\circ} \mathrm{N}$ and $10^{\circ} \mathrm{S}$ in latitude, and therefore it could not account for some of the observed features, such as current flows across the dip equator.

The three-dimensional University College London model 


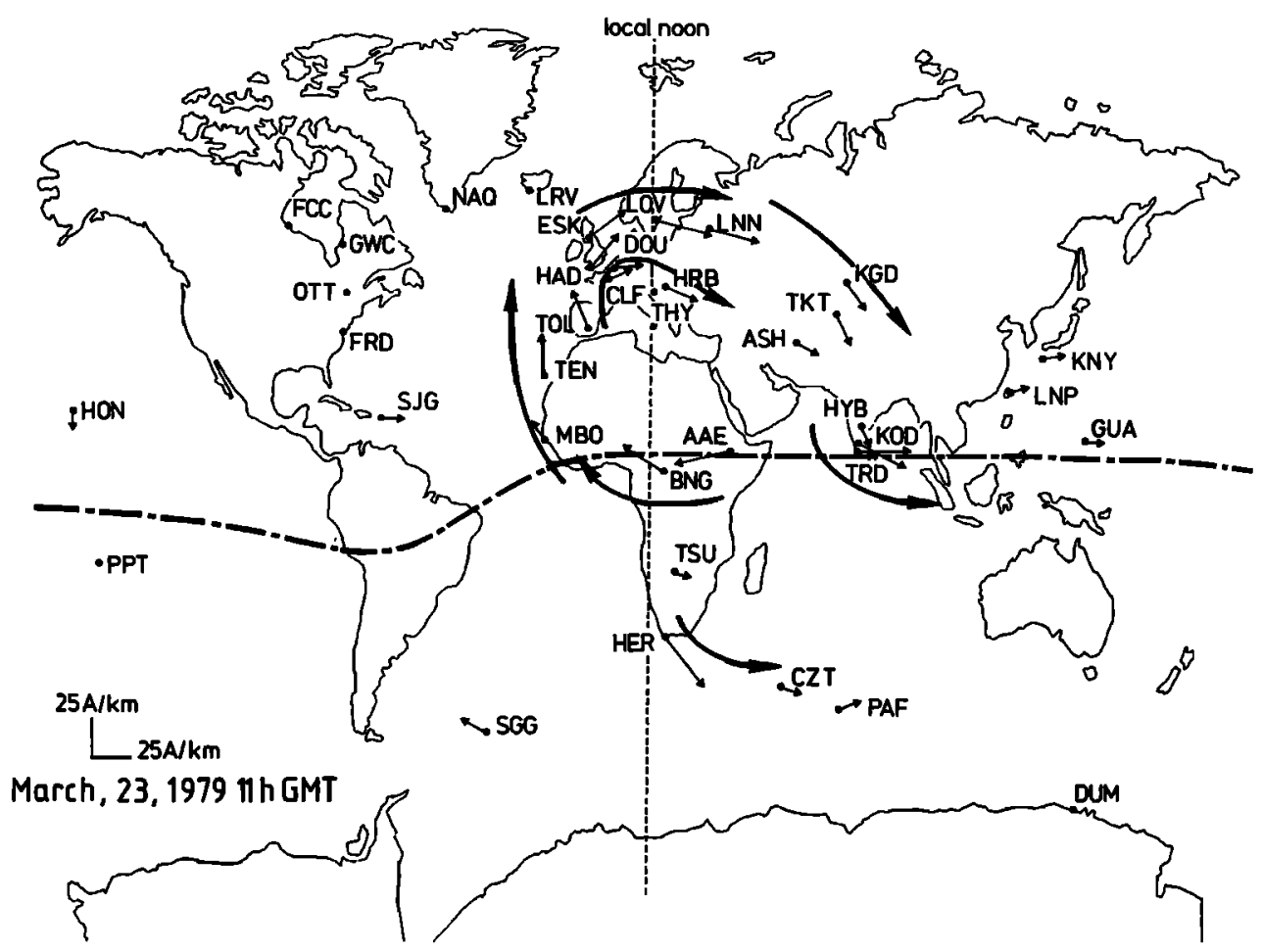

Fig. $7 a$

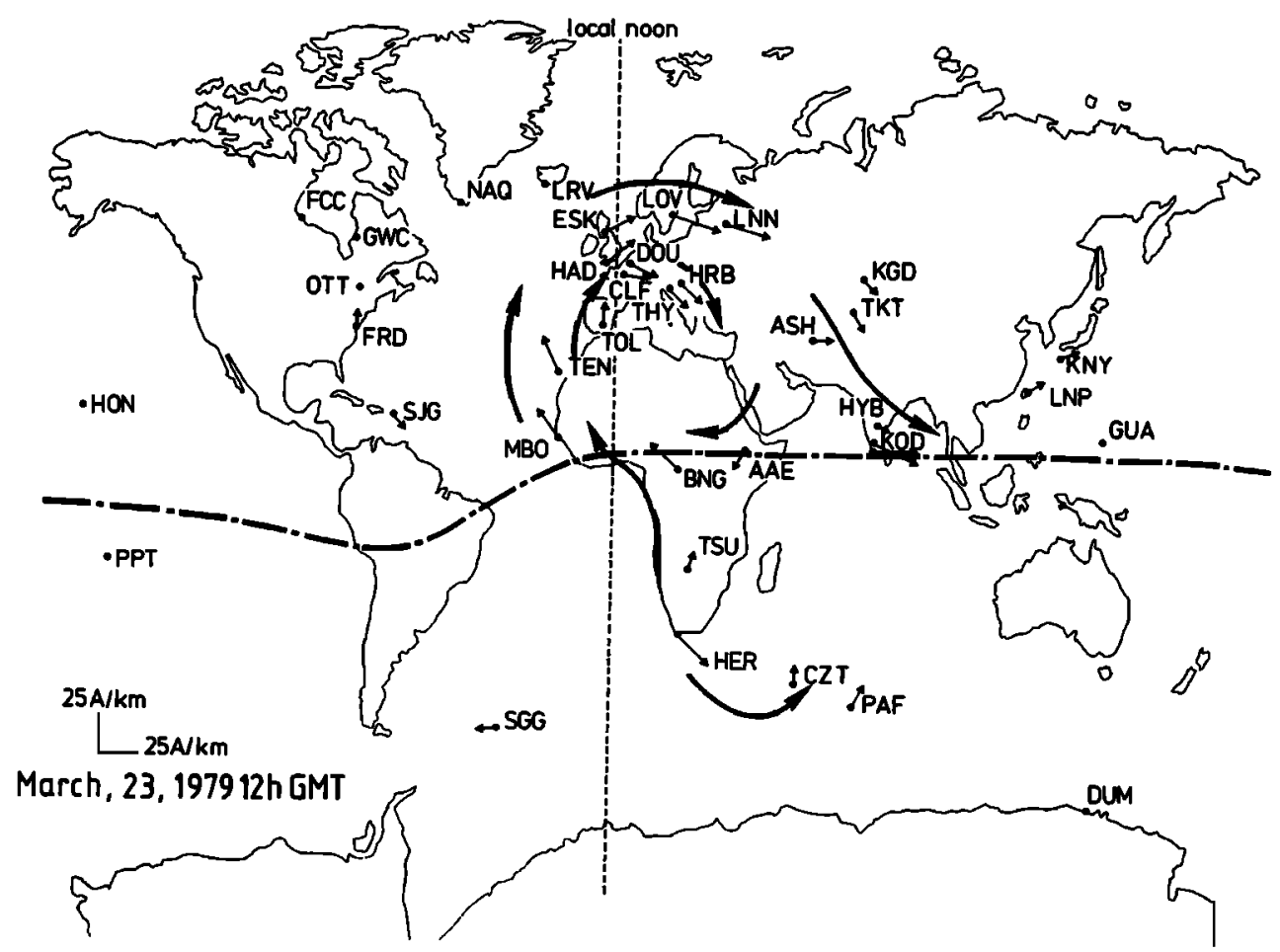

Fig. $7 b$

Fig. 7. Same as Figure 6 except the time is UT noon.

[Fuller-Rowell and Rees, 1980, 1984] predicted that neutral wind disturbances resulting from magnetospheric storms can cross the dip equator. The associated ground magnetic signature has not yet been simulated, thus preventing any comparison between these results and our data.

Thus concepts such as that of the invasion [Van Sabben,
1964; Mayaud, 1965a] or the counterelectrojet [Gouin and Mayaud, 1967, 1969; Fambitakoye, 1976; Fambitakoye and Mayaud, 1976] introduced to account for morphological observations at low latitudes may correspond to disturbed ionospheric dynamo processes partly responsible for the $S_{R}$ day-to-day variability described by Mayaud [1967]. These 


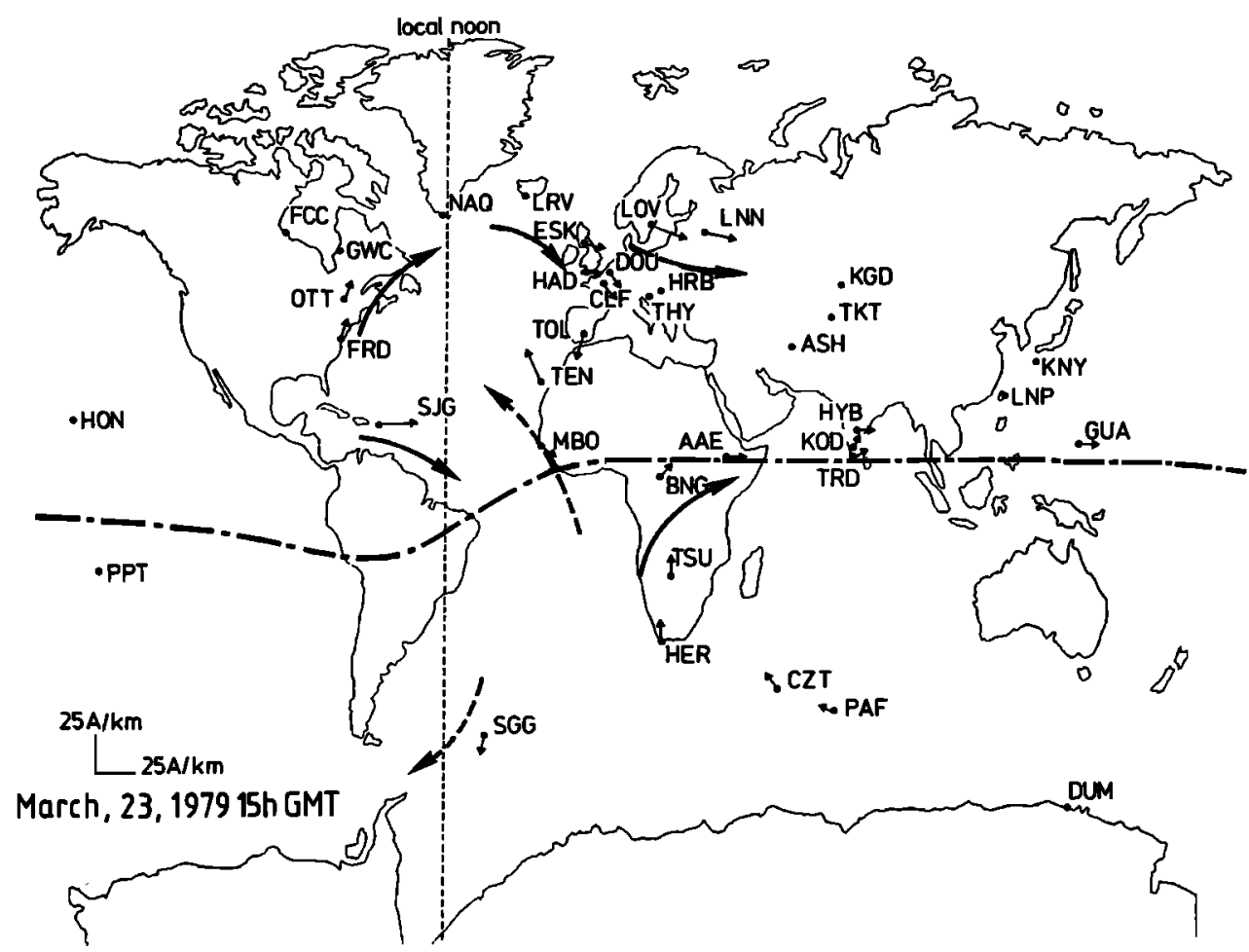

Fig. $8 a$

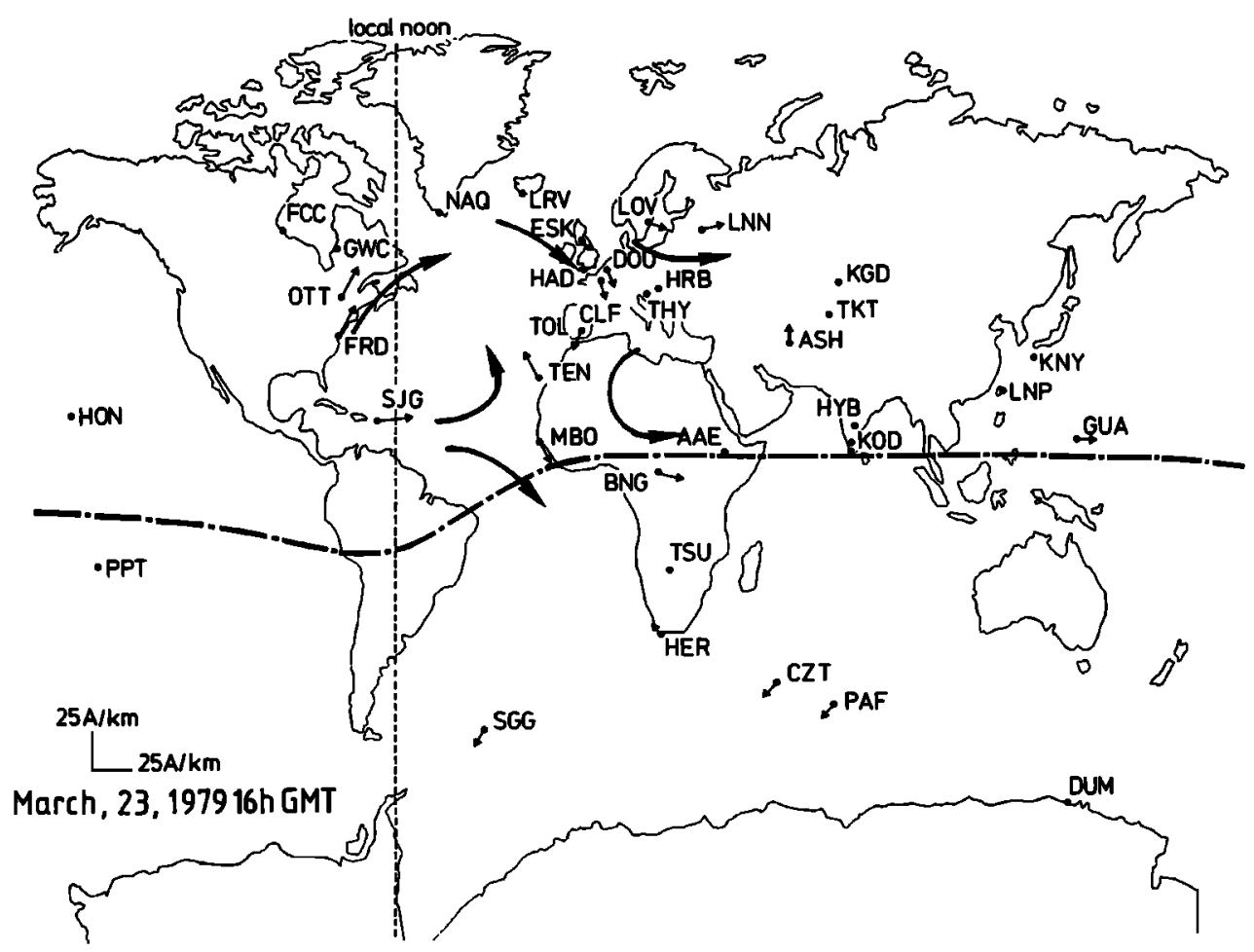

Fig. $8 b$

Fig. 8. Same as Figure 6 except the time is UT late afternoon.

studies show that geomagnetic data and results from in situ measurements (radar, satellite, etc.) complement one another well. They also suggest that the magnetic observations made at permanent observatories over about 100 years are a valuable data set to aid the study of these processes.
Acknowledgments. The authors are indebted to Art Richmond for fruitful scientific discussions and for help in correcting the English. We also thank one unknown referee for his helpful comments. One of us (O.F.) wishes to thank Y. Albouy, G. Just, D. Remy, and C. Mullon for their assistance in solving technical problems. 
The Editor thanks T. Araki and another referee for their assistance in evaluating this paper.

\section{REFERENCES}

Bernard, R., Etude de la variabilité des marées atmosphériques mesurées par radar météorique et sondeur à diffusion incohérente, thèse d'etat, Univ. de Paris, Paris, 1978.

Blanc, M., and A. D. Richmond, The ionospheric disturbance dynamo, J. Geophys. Res., 85, 1669, 1980.

Chapman, S., and J. Bartels, Geomagnetism, Oxford at the Clarendon Press, London, 1940.

Fambitakoye, O., Etude des Effets Magnétiques de l'Electrojet Equatorial, Ser. Geophys., vol. 14, ORSTOM, Bondy, France, 1976.

Fambitakoye, O., and P. N. Mayaud, Equatorial electrojet and regular daily variation $S_{R}, \mathbf{I}$, A determination of the equatorial electrojet parameters, J. Atmos. Terr. Phys., 38, 1, 1976.

Fuller-Rowell, T. J., and D. Rees, A three dimensional, timedependent global model of thermosphere, J. Atmos. Sci., 37, 2545,1980 .

Fuller-Rowell, T. J., and D. Rees, Interpretation of an anticipated long lived vortex in the lower thermosphere following simulation of an isolated substorm, Planet. Space Sci., 32, 69, 1984.

Gouin, P., and P. N. Mayaud, Contre-électrojet équatorial et nappes de courants $S q$ inversés, $C$. $R$. Acad. Sci., Ser. B, 268, 357, 1967.

Gouin, P., and P. N. Mayaud, A propos de l'existence possible d'un "contre-électrojet" aux latitudes magnétiques équatoriales, Ann. Geophys., 23, 41, 1969.

Kamide, Y., Electrodynamic Processes in the Earth's Ionosphere and Magnetosphere, Kyoto Sangyo University Press, Kyoto, Japan, 1988.

Kamide, Y., and A. Brekke, Auroral electrojet current density from the Chatanika radar and from the Alaska meridian chain of magnetic observations, J. Geophys. Res., 80, 587, 1975.

Mayaud, P. N., Analyse morphologique de la variabilité jour à jour de la variation "régulière" $S r$ du champ magnétique terrestre, 1 , Le système de courants $C_{p}$, Ann. Geophys., 21, 369, $1965 a$.

Mayaud, P. N., Analyse morphologique de la variabilité jour à jour de la variation "régulière" $S r$ du champ magnétique terrestre, 2 Le système de courants $C_{m}$ (régions non polaires), Ann. Geophys., 21, 515, $1965 b$.

Mayaud, P. N., Corrélation entre les variations journalières du champ magnétique terrestre sous l'electrojet équatoriales et dans les régions avoisinantes, Ann. Geophys., 23, 387, 1967.

Mayaud, P. N., Derivation, Meaning and Use of Geomagnetic Indices, Geophys. Monogr. Ser. vol. 22, 154 pp., AGU, Washington, D. C., 1980.

Mayaud, P. N., Comment on the "Ionospheric disturbance dynamo" by M. Blanc and A. D. Richmond, J. Geophys. Res., 87 $6353,1982$.

Mazaudier, C., Electric currents above Saint-Santin, 3, A prelimi- nary study of disturbances: June 6, 1978; March 22, 1979; March 23, 1979, J. Geophys. Res., 90, 1355, 1985.

Mazaudier, C., On the relationship between ionospheric phenomena and the day-to-day variability of the Earth's magnetic field regular variation "Sr", Doc. Travail 1177, Cent. Natl. d'Etudes des Télécommun., Issy-les-Moulineaux, France, 1989.

Mazaudier, C., and S. V. Venkateswaran, Delayed ionospheric effects of the geomagnetic storm of March 22, 1979 studied by the Sixth Co-ordinated Data Analysis Workshop (CDAW-6), Ann. Geophys., in press, 1990.

Mazaudier, C., R. Bernard, and S. V. Venkateswaran, Saint-Santin observations of lower thermospheric storms, J. Geophys. Res., 90, 2885, 1985. (Correction, J. Geophys. Res., 90, 6685, 1985.)

McPherron, R. L., and R. H. Manka, Dynamics of the 1054 UT March 22, 1979, substorm event: CDAW 6, J. Geophys. Res., 90, 1175,1985

Menvielle, M., C. Mazaudier, and A. Berthelier, On the determination of $\mathrm{K}$ indices by computer, paper presented at 19th General Assembly, Int. Union of Geod. and Geophys., Vancouver, B. C., Canada, Aug. 9-22, 1987.

Reddy, C. A., Evidence of a meridional circulation cell in lower thermosphere during a magnetic storm, J. Atmos. Phys., 36, 1561, 1974.

Richmond, A. D., and S. Matshushita, Thermospheric response to a magnetic substorm, J. Geophys. Res., 80, 2839, 1975.

Senior, C., and M. Blanc, Convection in the inner magnetosphere: Model predictions and data, Ann. Geophys., Ser. A, 87/06, 405, 1987.

Stening, R. J., A calculation of ionospheric currents due to semidiumal antisymmetric tides, J. Geophys. Res., 94, 1525, 1989.

Taïeb, C., and P. Poinsard, Modelling of the mid-latitude ionosphere: Application to storm effects, II, Ann. Geophys., 2-3, 359, 1984.

Van Sabben, D., North south asymmetry of Sq, J. Atmos. Terr. Phys., 26, 1187, 1964.

Vasyliunas, V. M., Mathematical models of magnetospheric convection, in Particles and Fields in the Magnetosphere, edited by B. M. McCormac, p. 60, D. Reidel, Hingham, Mass., 1970.

Vasyliunas, V. M., The interrelationship of magnetospheric processes, in Earth's Magnetospheric Processes, edited by B. M. McCormac, p. 29, D. Reidel, Hingham, Mass., 1973.

O. Fambitakoye, Laboratoire de Géophysique, ORSTOM, 70-74 route d'Aulnay, F-93140 Bondy, France.

C. Mazaudier, CNET/CRPE, 4 Avenue de Neptune, F-94107 Saint Maur des Fossés Cédex, France.

M. Menvielle, Laboratoire de Géomagnétisme, IPGP-Tour 14, 4 Place Jussieu, F-75252 Paris Cédex 05, France.

(Received August 10, 1989;

revised December 28, 1989; accepted December 29, 1989.) 